\title{
TEKNIK ASTOPHOTOGRAFI DALAM PENENTUAN POLA AKHIR SENJA (HILANGNYA MEGA MERAH) SEBAGAI AWAL MASUKNYA WAKTU ISYA DENGAN IMAGE PROCESSING
}

\author{
Arif Septianto*, Harry Ramza, Rosalina
}

Fakultas Teknik Universitas Muhammadiyah Prof. DR. HAMKA, e-mail*: arifseptianto02@gmail.com

\begin{tabular}{c|c|c}
\hline Diterima 9 Oktober 2021 & Disetujui 17 Januari 2022 & Dipublikasikan 27 Januari 2022 \\
\hline \multicolumn{3}{l|}{ https://doi.org/10.33369/jkf.4.3.221-228 } \\
\hline
\end{tabular}

\begin{abstract}
ABSTRAK
Penggunaan drone dalam teknik astofotografi menjadi solusi atas permasalahan pengukuran kecerlangan langit untuk mengetahui hilangnya waktu syafaq mengunakan SQM yang dinilai kurang efisien. Pada kasus menentukan awal waktu isya ditandai dengan hilangnya mega merah (syafaq) pada langit sebelah barat saat malam hari. Dalam peneitian pengukuran citra langit peneliti menggunakan teknologi drone sebagai sensor image. Data foto yang diambil pada penelitian ini diambil dalam rentang $15 \mathrm{sekon/} \mathrm{capture.} \mathrm{Data} \mathrm{yang} \mathrm{didapat} \mathrm{tidak} \mathrm{dapat} \mathrm{langsung} \mathrm{di} \mathrm{gunakan} \mathrm{karna} \mathrm{masih}$ terdpat noise. Karnanya perlu dihilangkan terlebih dahulu dengan metode image processing agar data tersebut dapat terlihat jelas dan mudah direpresentasikan oleh mata manusia atau komputer yang sifatnya deterministik. Metode pengolahan data pada penelitian ini menggunakan Microsoft Excel dan MATLAB dengan persamaan polynomial 5 untuk memplot grafik kecerahan langit. Hasil pada penelitian ini menunjukan bahwa waktu hilangnya syafaq berbedabeda pada setiap harinya. Waktu paling awal hilangnya syafaq terjadi pada pukul 18:38:18 dan waktu paling akhir terjadi pada pukul 18:59:19
\end{abstract}

Kata kunci : Astrofotografi, waktu syafaq, Image Processing

\begin{abstract}
The use of drones in astophotograpic techniques is asolution to the problem of measuring sky brightness to find out the loss of syafaq time using SQM which is considered less efficient. In the case of determining the start of Isha time, it is marked by the disappearance of the red mega (syafaq) in the western sky at night. In measuring the sky image, the researcher uses drone technology as an image sensor. Photo data taken in this study were taken in the span of 15 seconds/capture. The data obtained cannot be used directly because there is still noise. Because it needs to be removed first with the image processing method so that the data can be seen clearly and easily represented by the human eye or computer which is deterministic in nature. The data processing method in this study uses Microsoft Excel and MATLAB with polynomial 5 equations to plot the sky brightness graph. The results of this study indicate that the time of loss of syafaq is different every day. The earliest time the loss of syafaq occurred at 18:38:18 and the latest time occurred at 18:59:19.
\end{abstract}

Keywords : Astrofotografi, syafaq time, Image Processing

\section{PENDAHULUAN}

Dalam ilmu astronomi penentuan waktu shalat data astronomi yang di butuhkan meliputi: ketinggian, awal fajar, Matahari terbit, titik kulminasi, jarak zenit, Matahari terbenam, data geografis (lintang dan bujur), tanggal dan lokasi(1). Pada kasus menentukan awal masuknya waktu isya contohnya ditandai dengan hilangnya mega merah (syafaq) pada langit sebelah Barat saat malam hari. Mega merah (syafaq) dapat terlihat bergantung pada kondisi kecerlangan langit pada malam hari dengan nilai kelembaban tertentu. Karna sebab itu mutu langit berubah seiring dengan perubahan kelembaban udara. Hal ini relevan dengan peneliian BMKG kelembaban udara dengan nilai yang cukup tinggi (70-100\%) menandakan kandungan uap air yang cukup besar untuk proses pertmbuhan awan-awan konvektif (cumulonimbus) yang dapat menimbulkan hujan sedang hingga lebat disertai angin kencang(2). 
Astrofotografi merupakan pengamatan fenomena benda langit dan diabadikan melalui foto(3). Hal ini dapat dilakukan dengan sederhana melalui kamera Digital Single Lens Reflex (DSLR) maupun dengan teropong yang canggih. Pada penentuan waktu salat, adalah hal yang paling fundamental bagi umat muslim karna merupakan salah satu syarat sah ibadah tersebut diterima atau tidak. Dalam Al- Qur'an surat An- Nisa :103 konsekuensi logis dari ayat ini adalah salat tidak bisa dilakukan sembarang waktu, melainkan harus mengikuti atau berdasarkan dalildalil baik Al-Qur'an maupun Hadist(4). Penenentuan akurat waktu zuhur, ashar, maghrib tidak begitu sulit karna dapat dengan jelas diukur dengan panjang bayangan melalui pergerakan posisi matahari(5).

Pengukuran kecerahan langit yang dilakukan oleh peneliti astronomi dilakukan dengan menggunakan peralatan sederhana Sky Quality Meter (SQM)(6). Perubahan kegelapan langit pada gerhana Matahari juga dapat diukur dengan SQM(7). Sayangnya data yang di dapat pada alat SQM mudah untuk dimanipulasi karna hanya terdapat data angka saja. Persoalan akan muncul dalam analisis data hasil SQM adalah data yang sangat banyak dan memerlukan waktu(8). Maka dari itu perlunya adanya teknologi modern dalam ranah astronomi yang menjadi solusi dari permasalahan tersebut.

Saat ini teknologi untuk memenuhi kebutuhan manusia sudah berkembang pesat,khusunya dalam bidang teknologi, informasi, kounikasi, seperti drone. Drone atau pesawat tanpa awak Unmanned Aerial Vehicle (UAV) adalah solusi mendapatkan data dengan efektif dan efisien(9). Drone adalah perangkat yang dilengkapi dengan sistem pengendali terbang via gelombang, navigasi presisi (GPS) dan elektronik control penerbangan sehingga mampu terbang sesuai perencanaan terbang autopilot(10). Drone biasanya juga dilengkapi dengan sensor kamera resolusi tinggi dan dapat melakukan pemotretan foto di udara. Penggunaan drone menghasilkan gambar/citra dengan resolusi spasial yang besar, tidak terkendala awan karena pengoprasiaannya pada ketinggian dibawah awan. Hal tersebut dapat menjawab kesulitan aksesibilitas dilapangan, termasuk masalah citra satelit yang kurang detil. Bahkan tingkat kedetilan citra satelit adalah 15 x 15 meter, sementara pada drone menghasilkan pemantauan hingga 2 centimeter per pixel.

Dari kelebihan tersebutlah peneliti menggunakan drone sebagai alat pengambilan data, pengambilan data dilakukan dengan kriteria tertentu seperti cuaca terang, minimal berawan, tidak berangin serta tidak ada hilal (bulan sabit). Selain itu polusi cahaya saat malam hari dapat diartikan sebagai kadaan dimana organisme terkena cahaya malam di tempat yang salah, pada waktu yang salah atau pada intensitas yang salah, yang merupakan hasil dari penerangan listrik, atau lampu buatan yang berlebihan dan mencolok disebabkan oleh desain pencahayaan yang buruk. Polusi buatan meningkat 6\% setiap tahun selama 6 dekade terakhir. Dampak buruk dari polusi cahaya saat malam hari pada hewan dan serangga dapat mengganggu reproduksi alami mereka, perilaku bersarang, migrasi, menyebabkan disorientasi, kebutaan, dan kematian tinggi karna kelelahan(11).

Terdapat dua waktu salat yang bergantung pada waktu awal dan akhir senja astronomi yaitu salat subuh dan isya(12). Persoalan muncul dalam pengambilan data menggunakan SQM adalah data yang sangat banyak, dengan total data bisa mencapai 300 data, selain itu juga data tersebut rentan dimanipulasi karna hanya berupa data angka yang tidak dapat di validasi. Hal tersebut berbeda dengan penggunaaan drone sebagai alat pengambilan data. Sehingga peneliti mengambil judul Analisis citra untuk menentukan hilangnya syafaq (mega merah) sebagai awal masuknya waktu isya menggunakan drone dengan metode polinomial 5. Penelitian ini bertujuan untuk mengetahui waktu dan posisi ketinggian fajar pada saat hilangnya syafaq sebagai penenda awal masuknya waktu salat melalui pemrosesan data pada Imagej, MATLAB, maupun Microsoft Excel.

\section{METODE PENELITIAN}

Metode Penelitian yaitu field research (studi lapangan) pengambilan data dilakukan dengan kondisi cuaca yang sangat cerah dan tidak berangin. Pengumpulan data dilaksanakan di kawasan kampus FKIP UHAMKA, Kampung Rambutan, Ciracas, Jakarta timur, Daerah Khusus Ibukota 
Jakarta, Indonesia dengan titik koordinat longitude -6.303291 dan latitude 106.872089 yang diambil dengan durasi 1jam yaitu dari pukul 18:17 sampai 19:17 WIB. Dengan rentan waktu pengambilan foto setiap 15 sekon dengan 3 baterai, yang setiap baterai dapat bertahan \pm 20 menit yang artinya kurang lebih drone dapat melakukan penerbangan untuk pengambilan data dengan durasi \pm 1 jam. Terdapat 7 data yang terkumpul artinya ada 7 hari pengumpulan datanya.

Tabel 1. Frekuensi pengumpulan data

\begin{tabular}{ccccc}
\hline No & Hari & Tanggal & Bulan & Tahun \\
\hline 1 & Kamis & 11 & Maret & 2021 \\
2 & Jum'at & 12 & Maret & 2021 \\
3 & Sabtu & 13 & Maret & 2021 \\
4 & Selasa & 16 & Maret & 2021 \\
5 & Kamis & 25 & Maret & 2021 \\
6 & Kamis & 1 & April & 2021 \\
7 & Jum'at & 2 & April & 2021 \\
\hline
\end{tabular}

Proses atau teknik pengambilan data menggunakan drone, drone dinilai lebih fleksibel dalam melakukan pengambilan data kecerlangan langit. Penggunaan drone adalah pilihan yang sangat tepat. Penggunaan drone menghasilkan gambar/citra dengan resolusi parsial yang cukup besar, tidak terkendala awan, karna pengoprasiannya dibawah ketinggian awan(13). Rentang waktu yang diambil pada pengambilan data yaitu 15 sekon/ capture foto. Yang artinya dalam satu kali pengambilan data di dapat 214 data foto. Dengan posisi ketinggian drone 18-20 meter dari rooftop gedung 3 lantai. Penggunaan drone jenis ini dengan alasan karena hasil foto yang dihasikan memiliki resolusi spasial yang tinggi dan juga harga yang masih terjangkau. Karena citra syafaq sering mengalami penurunan mutu (degradasi), misalnya mengadung derau (noise), warnanya terlalu kontras, kurang tajam dan sebagainya. Sehingga noise ini perlu dihilangkan dengan metode tertentu sehingga obyek yang ingin dideteksi dapat terlihat lebih jelas(14). Maka dari itu perlu adanya image processing, image processing atau pengolahan citra merupakan suatu metode atau teknik yang dapat digunakan untuk memproses citra atau gambar dengan jalan memanipulasinya menjadi sebuah gambar yang diisikan untuk mendapatkan informasi tertentu mengenai obyek yang sedang diamati(15). Pengolahan citra ini bertujuan untuk memperbaiki kualitas gambar atau citra agar mudah di representasikan oleh indra penglihatan manusia ataupun teknologi komputer(16).

Tabel 2. Spesifikasi Drone DJI Mavic Mini Quadcopter

\begin{tabular}{cc}
\hline DJI Mavic Mini & Quadcopter \\
\hline Berat & 249 Gram \\
Metode Ploting & FPV ( Vidio ploting) \\
Kamera & 2.7k Camera 3-Axis Gimbal \\
Resolusi Spectral & 3 Visible-light channels (RGB) \\
Resolusi Radiometris & 8 -bit \\
Kapasitas Baterai & $2600 \mathrm{mAh}$ \\
Dimensi (W x H x D) & $159 \times 202 \times 55 \mathrm{~mm}$ \\
\hline
\end{tabular}

\subsection{Alur Pelaksanaan Penelitian}

Pada tahap ini adalah tahap alur pelaksanaan kerja, dimana peneliti dalam melaksanakan penelitian seperti dengan flowchart dibawah ini, agar pelaksanaanya berjalan dengan baik dan menghasilkan data sesuai dengan apa yang diinginkan. Pada alur pelaksanaan tahap awal yaitu memulai atau awal untuk melaksanakan penelitian, yang kemudian dilanjutkan dengan persiapan alat yang di butuhkan pada pelaksanaan penelitian, pada tahap selanjutnya adalah pemotongan noise pada data foto, pada tahap pengolahan data, data foto yang bebas dari noise kemudian di proses. Setelah data di proses tahap selanjutnya yaitu menentukan titik potong pada data yang telah selesai diolah. 


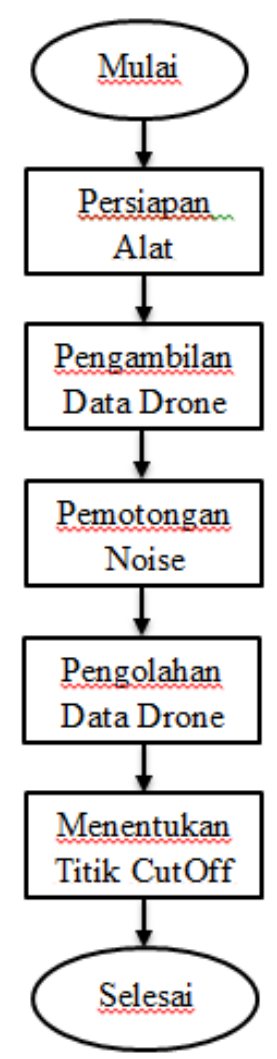

Gambar 1. Flowchart Alur Penelitian

\section{2 Tahapan pengambilan dan pengolahan data}

Secara teknis tahapan dalam melakukan pengambilan dan pengolahan data pada penelitian ini adalah sebagai berikut: 1) Mempersiapkan alat yang dibutuhkan dalam pelaksanaan penelitian yaitu: Drone, Laptop, dan smartphone sebagai control dan monitoring pengambilan gambar; 2) pengambilan data mengunakan drone, data yang di ambil berupa data foto yang di ambil secara kontinyu selama 15 detik/ capture; 3) waktu pengambilan data dimulai pukul $18.17 \mathrm{WIB}$; 4) setelah pengambilan data telah selesai dilakukan, kemudian data tersebut dilakukan pemotongan noise; 5) hasil data yang telah dilakukan pemotongan noise kemudian dianalisis menggunakan image procesing yang berupa aplikasi ImageJ dengan hasil berupa standar deviasi; 6) setelah itu dilakukan pencarian DIP (derajat ketinggian matahari) dengan memasukan koordinat lokasi serta waktu setiap menit pada NOAA; 7) data hasil dari analisis tersebut kemudian di copy ke Microsof excel yang berisikan photo id, standar deviasi, time, dan DIP; 8) data tersebut kemudian di plot menjadi sebuah grafik dengan menggunakan pendekatan polynomial 5; 9) kemudian data di proses menggunakan mathlab dengan pendekatan polynomial 5 ; 10) kemudian memberikan program input dengan memasukan input number dan input matrix yang sesuai pada data di Microsoft Excel agar data dapat dimasukan dan di proses oleh matlab; 11) setelah itu data nomor, photo id, standar deviasi, time dan DIP diplot sehingga muncul grafik dan dilihat diwaktu berapakah titik potong grafik yang bersinggungan, maka itulah waktu hilangnya waktu syafaq sebagai tanda masuknya waktu isya.

\section{HASIL DAN PEMBAHASAN}

\subsection{Pengolahan Data}

Aplikasi atau software yang digunakan dalam analis citra adalah ImageJ dan Microsoft Excel. Adapun tahapannya adalah sebagai berikut:

1. Data dibawah ini merupakan data hasil crop yang akan dianalisis dengan ImageJ untuk menentukan nilai standar deviasi. 
Teknik Astophotografi dalam Penentuan Pola Akhir Senja (Hilangnya Mega Merah) sebagai Awal Masuknya Waktu.... Arif Septianto, Harry Ramza, Rosalina

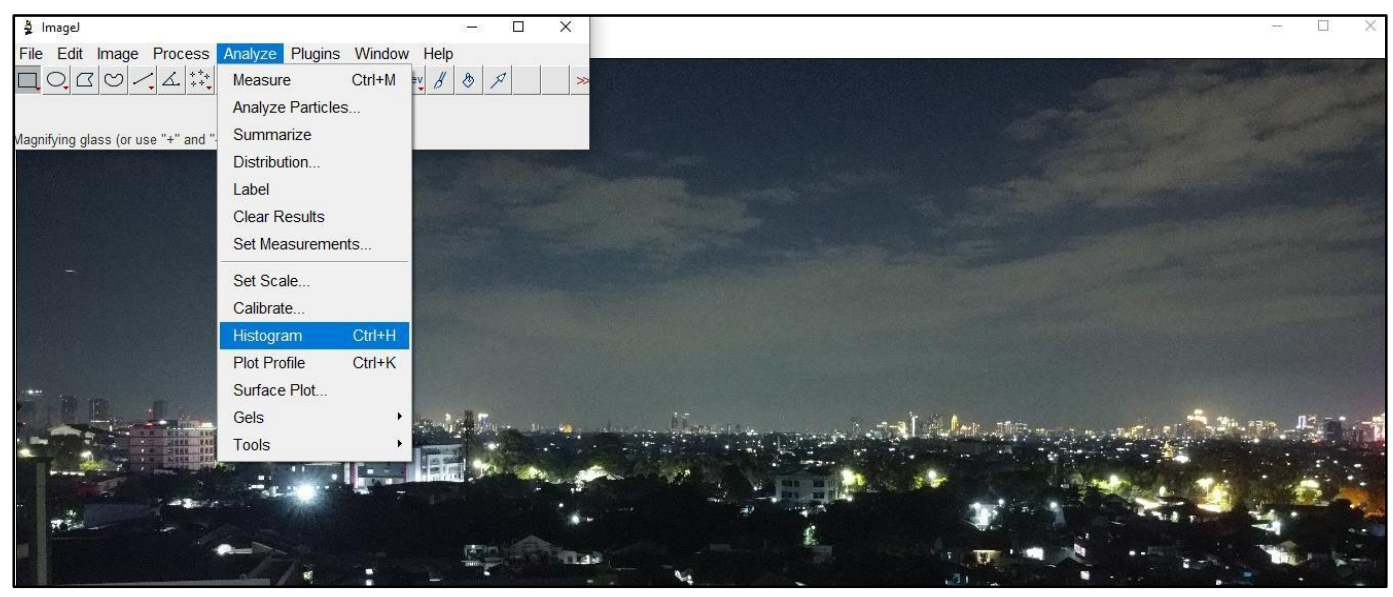

Gambar 2. Tampilan Pemrosesan Data pada ImageJ

2. Selanjutnya data dibawah ini adalah nilai standar deviasi dari data foto yang telah di analyze yang berupa histogram RGB.

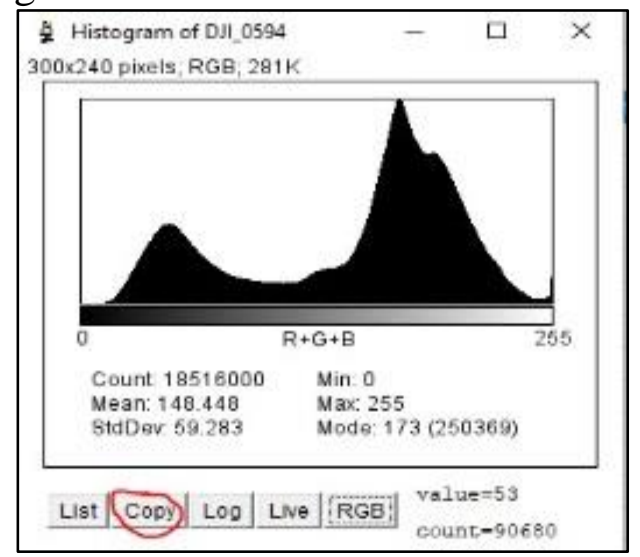

Gambar 3. Tampilan Nilai Standar Deviasi

3. Menentukan nilai DIP dengan NOAA, dengan memasukkan lokasi dan waktu detail pada saat di lakukan pengambilan data.

\begin{tabular}{|c|c|c|}
\hline \multicolumn{3}{|c|}{$\begin{array}{l}\text { Calculation of solar azimuth and elevation based on the calculation procedure by NOAA } \\
\text { (http://www.srrb.noaa.gov/highlights/sunrise/azel.html) }\end{array}$} \\
\hline Input & & \\
\hline $\begin{array}{l}\text { latitude in decimal degrees (positive in northern hemisphere) } \\
\text { longitude in decimal degrees (negative for western hemisphere) } \\
\text { year } \\
\text { month } \\
\text { day } \\
\text { hours } \\
\text { minutes } \\
\text { seconds } \\
\text { time zone in hours relative to GMT/UTC (PST }=-8, \mathrm{MST}=-7, \mathrm{CST}=-6, \mathrm{EST}=-5 \text { ) } \\
\text { daylight savings time (no= } 0 \text {, yes }=1 \text { ) }\end{array}$ & $\begin{array}{l}-6.303 \\
106.870 \\
2021 \\
4 \\
2 \\
18 \\
17 \\
15 \\
7 \\
0\end{array}$ & Ciracas \\
\hline $\begin{array}{l}\text { Output } \\
\text { solar azimuth (degrees clockwise from north) } \\
\text { solar elevation (degrees from horizon) }\end{array}$ & 274.52 & \\
\hline
\end{tabular}

Gambar 4. Tampilan Nilai DIP

4. Data berikut hasil pengolahan data dan di-copy ke dalam Microsoft Excel

\begin{tabular}{|c|c|c|c|c|c|}
\hline 4 & A & B & C & D & $E$ \\
\hline 1 & No & Photo ID & tandart De & Time & DIP (deg) \\
\hline 2 & 1 & 594 & 59.283 & 18.17.15 & -5.76 \\
\hline 3 & 2 & 596 & 59.943 & 18.18 .15 & -6.01 \\
\hline 4 & 3 & 600 & 59.103 & 18.19 .15 & -6.26 \\
\hline 5 & 4 & 604 & 56.952 & 18.20 .15 & -6.51 \\
\hline 6 & 5 & 608 & 54.944 & 18.21.15 & -6.76 \\
\hline 7 & 6 & 612 & 52.743 & 18.22 .15 & -7.01 \\
\hline 8 & 7 & 616 & 51.642 & 18.23 .15 & -7.26 \\
\hline 9 & 8 & 620 & 48.917 & 18.24 .15 & -7.51 \\
\hline 10 & 9 & 624 & 47.157 & 18.25 .15 & -7.76 \\
\hline
\end{tabular}

Gambar 5. Tabel Data yang Diperlukan 
5. Berikut program MATLAB menggunakan persamaan polynomial 5.

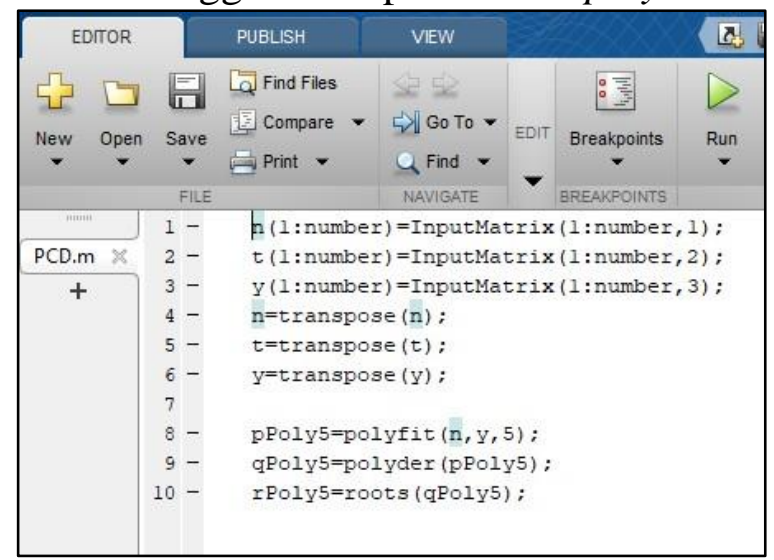

Gambar 6. Program Persamaan Polynomial 5 pada MATLAB

6. Hasil program command window, kemudian data pada Microsoft Excel dimasukkan sesuai banyaknya data.

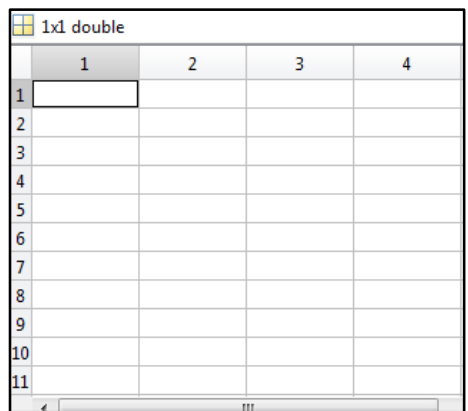

Gambar 7. Tabel Data yang Diperlukan

7. Persamaan polynomial yang didapat dari program MATLAB ketika dijalankan.

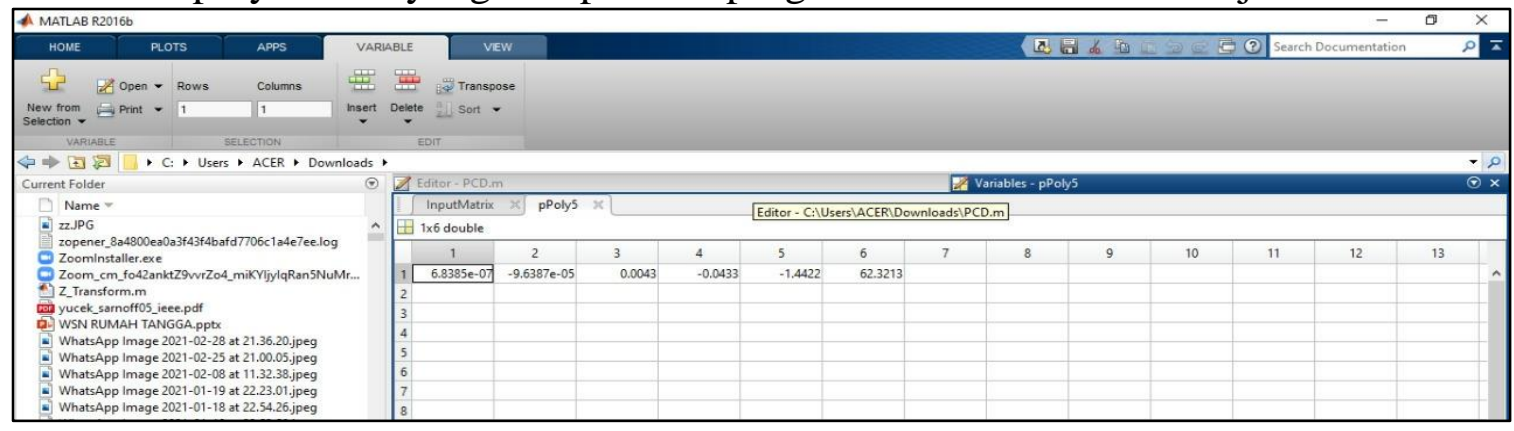

Gambar 8. Tabel Persamaan yang Dihasilkan dari Program MATHLAB

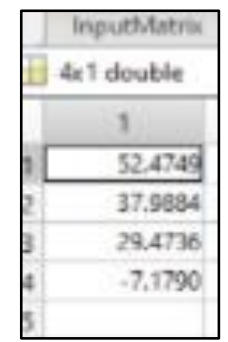

Gambar 9. Tabel Data Hasil MATLAB

\begin{tabular}{|lrrrl|l|}
\hline & \multicolumn{1}{l}{ No } & Photo Id & Waktu & \\
X1 & 52.4749 & 790 & 19.11 .15 & \\
X2 & 37.98844 & 732 & 18.54 .15 & \\
X3 & 29.47362 & 700 & 18.46 .15 & Cut Off \\
X4 & -7.17904 & 616 & 18.23 .15 & \\
\hline
\end{tabular}

Gambar 10. Tabel Data yang Sudah Dipindah ke Microsoft Excel

Gambar tabel diatas adalah data yang dihasilkan menggunakan program MATLAB yang mana pada gambar table tersebut digunakan dalam penentuan titik CutOff (pancung) pada 
grafik yang telah diplot sebelunya pada Microsoft Excel.

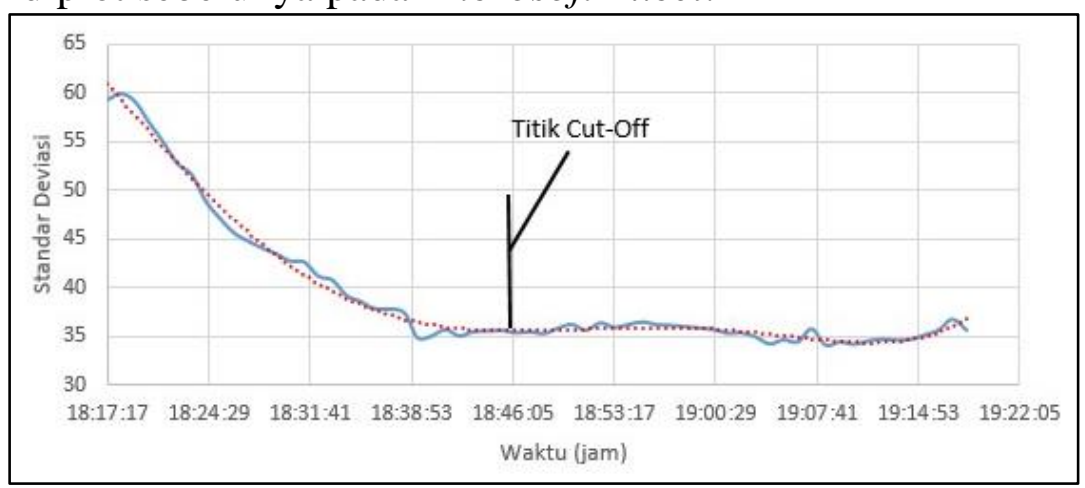

Gambar 9. Grafik Tanggal 02-04-2021 hasil plot pada Microsoft Excel

Grafik diatas merupakan grafik dari hasil data yang sudah di plot pada menu Microsoft Excel. Grafik tersebut menerangakan standar deviasi terhadap waktu dengan menunjukkan nilai keceranhan langit yang semakin geap ditunjukkan dengan semakin menurunnya garis biru. Sehingga titik CutOff ( titik pancung) berdasarkan data diatas pada pukul 18:46:15, yang dimana kedua garis bersinggungan antara garis biru (data fisik) dan garis merah putus-putus (data matematis).

\begin{tabular}{|r|r|r|r|r|r|r|r|r|r|}
\hline No & Photo ID & Standart Dev & Time & DIP (deg) & No & Photo ID & Standart Dev & Time & DIP (deg) \\
\hline 1 & 594 & 59.283 & 18.17 .15 & -576 & 21 & 668 & 37.563 & 18.38 .15 & -11 \\
\hline 2 & 596 & 59.943 & 18.18 .15 & -6.01 & 22 & 672 & 34.928 & 18.39 .15 & -11.24 \\
\hline 3 & 600 & 59.103 & 18.19 .15 & -6.26 & 23 & 676 & 35.058 & 18.40 .15 & -11.49 \\
\hline 4 & 604 & 56.952 & 18.20 .15 & -6.51 & 24 & 680 & 35.745 & 18.41 .15 & -11.74 \\
\hline 5 & 608 & 54.944 & 18.21 .15 & -6.76 & 25 & 684 & 35.079 & 18.42 .15 & -11.99 \\
\hline 6 & 612 & 52.743 & 18.22 .15 & -7.01 & 26 & 688 & 35.534 & 18.43 .15 & -12.24 \\
\hline 7 & 616 & 51.642 & 18.23 .15 & -7.26 & 27 & 692 & 35.567 & 18.44 .15 & -12.49 \\
\hline 8 & 620 & 48.917 & 18.24 .15 & -7.51 & 28 & 696 & 35.657 & 18.45 .15 & -12.74 \\
\hline 9 & 624 & 47.157 & 18.25 .15 & -7.76 & 29 & 700 & 35.39118 .46 .15 & -12.98 \\
\hline 10 & 628 & 45.659 & 18.26 .15 & -8.01 & 30 & 704 & 35.52 & 18.47 .15 & -13.23 \\
\hline 11 & 632 & 44.823 & 18.27 .15 & -8.26 & 31 & 708 & 35.318 & 18.48 .15 & -13.48 \\
\hline 12 & 636 & 44.112 & 18.28 .15 & -8.51 & 32 & 712 & 35.887 & 18.49 .15 & -13.73 \\
\hline 13 & 640 & 43.516 & 18.29 .15 & -8.76 & 33 & 716 & 36.255 & 18.50 .15 & -13.98 \\
\hline 14 & 644 & 42.769 & 18.30 .15 & -9.01 & 34 & 720 & 35.659 & 18.51 .15 & -14.23 \\
\hline 15 & 648 & 42.668 & 18.31 .15 & -9.25 & 35 & 724 & 36.4218 .52 .15 & -14.28 \\
\hline 16 & 652 & 41.21 & 18.32 .15 & -9.5 & 36 & 728 & 35.9618 .53 .15 & -14.72 \\
\hline 17 & 656 & 40.812 & 18.33 .15 & -9.75 & 37 & 732 & 36.25418 .54 .15 & -14.97 \\
\hline 18 & 660 & 39.22 & 18.34 .15 & -10 & 38 & 736 & 36.5118 .55 .15 & -15.22 \\
\hline 19 & 664 & 38.627 & 18.35 .15 & -10.25 & 39 & 740 & 36.23418 .56 .15 & -15.47 \\
\hline 20 & 667 & 37.883 & 18.36 .15 & -10.5 & 40 & 744 & 36.16418 .57 .15 & -15.72 \\
\hline
\end{tabular}

Gambar 10. Tabel Data 02-04-2021, Hasil Titik Cutoff yang Ditandai Blok Warna Kuning 3.2 Hasil Pengolahan Data

Tabel 3. Tabel data dengan waktu hilangnya syafaq

\begin{tabular}{cccccc}
\hline No & Hari & Tanggal & Bulan & Tahun & Waktu Hilangnya Syafaq \\
\hline 1 & Kamis & 11 & Maret & 2021 & $18: 59: 19$ \\
2 & Jum'at & 12 & Maret & 2021 & $18: 57: 34$ \\
3 & Sabtu & 13 & Maret & 2021 & $18: 51: 30$ \\
4 & Selasa & 16 & Maret & 2021 & $18: 38: 18$ \\
5 & Kamis & 25 & Maret & 2021 & $18: 45: 17$ \\
6 & Kamis & 1 & April & 2021 & $18: 51: 38$ \\
7 & Jum'at & 2 & April & 2021 & $18: 46: 15$ \\
\hline
\end{tabular}

Data diatas adalah data yang sudah di proses dan sudah melewati proses pengolahan data, dimana terdapat 7 data, yang dilakukan pengambilan data selama 7 hari. Semua data memiliki waktu berbeda pada saat hilangnya syafaq. Hal tersebut terjadi karena beberapa hal diantaranya polisi cahaya. Polusi cahaya dapat diartikan sebagai keadaan dimana suatu prtikel atau organisme terkena paparan cahaya ditempat yang salah, penempatan pencahayaan yang salah dan pencahayaan yang berlebihan dari konsep lighting yang tidak tepat. 


\section{SIMPULAN DAN SARAN}

\subsection{Simpulan}

Berdasarkan pada data yang diperoleh dan telah melewati peroses pengolahan data tersebut, dihasilkan bahwa waktu hilannya syafaq sebagai awal masuknya waktu isya dari 7 data tersebut, disimpulkan bahwa waktu hilangnya syafaq paling awal terjadi pada tanggal 18 Maret 2021 pada pukul 18:38:18, dan waktu paling akhir hilangnya syafaq pada tanggal 11 Maret 2021yaitu pada pukul 18:59:19. Hal tersebut relevan dengan Tono Saksono menurutnya jika dilihat daerah timur tengah mendapatkan nilai dip subuh $-18^{\circ}$ dan isya -16 , maka di Indonesia seharusnya lebih rendah dari itu, karena Indonesia terletak pada daerah ekuator.

\subsection{Saran}

Dalam penelitian ini menggunakan DIP (derajat ketinggian matahari) dalam menentukan waktu hilangnya syafaq sebagai awal masuknya waktu isya. Perlu kiranya dapat dijadikan pertimbangan bagi ilmuan falak dalam perhitungan awal waktu salat dalam mengunakan solar dip dapat dijadikan sebuah acuan atau pertimbangan.

\section{DAFTAR PUSTAKA}

1. Habibullah Ritonga1* AJRB-B. Peran Ilmu Falak Dalam Masalah Arah Kiblat, Waktu Salat dan Awal Bulan. 2016;2.

2. Kemdikbud. Hasil PISA Indonesia 2018: Akses Makin Meluas, Saatnya Tingkatkan Kualitas. Siaran Pers Nomor: 397/Sipres/A5.3/XII/2019. 2019. p. 1.

3. Qulub ST, Legault LT. Al-marshad: jurnal astronomi islam dan ilmu-ilmu berkaitan. 2018;5729(June).

4. Afaq AL, Almuhtadi AS. Syafaqul Ahmar dan Syafaqul Abyadh. 2019;1(1):67-88.

5. Ahyar M, Pramudya Y, Raisal AY. Penentuan Awal Waktu Subuh Menggunakan Sky Quality. Pros SNFA (Seminar Nas Fis dan Apl 2018. 2018;184-9.

6. Fisika MP, Dahlan UA, Umbulharjo K, Istimewa D, Tracker S. SMARTPHONE DAN SKY QUALITY METER BERBANTUAN TRACKER dan CMOS ( Complementary Metal-oxide Semiconductor ). Sensor CCD bekerja Microsoft Excel . Hasil analisis dibandingkan dan dihitung nilai luminance dan. 2021;05(01):65-73.

7. Kelsall T, Weiland L. The sky brightness measurement during the 2016 solar eclipse in Ternate. 2016;

8. Ahyar M, Pramudya Y, Okimustava O. Implementasi Sistem Pengolahan Data Sky Quality Meter Berbasis Visual Basic Untuk Analisis Perubahan Tingkat Kecerahan Langit. J Kumparan Fis. 2020;3(3):239-46.

9. Geodesi JT. Pemanfaatan Unmanned Aerial Vehicle ( UAV ) Jenis Quadcopter untuk Percepatan Pemetaan Bidang Tanah. 2018;2018(1):30-40.

10. Utomo B. DRONE UNTUK PERCEPATAN PEMETAAN BIDANG. 2017;18(2):146-55.

11. Azman MI, Dalimin MN, Mohamed M, Abu Bakar MF. A Brief Overview on Light Pollution. IOP Conf Ser Earth Environ Sci. 2019;269(1).

12. Raisal AY, Pramudya Y, Okimustava O, Muchlas M. The moon phases influence on the beginning of astronomical dawn determination in Yogyakarta. Int J Sci Appl Sci Conf Ser. 2017;2(1):1.

13. Stefano A. Pemanfaatan Drone dalam Pemetaan Kontur Tanah. 2020;16(02):32-41.

14. Sari IM, Arifin AZ, Yuniarti A. Deteksi Kemunculan Bulan Sabit. 2012;1(1):1-5.

15. Kendaraan P, Di B, Raya J. Pengolahan citra dengan menggunakan web cam pada kendaraan bergerak di jalan raya. 2016;1:1-6.

16. Sugiarti S. Peningkatan Kualitas Citra Dengan Metode Fuzzy Possibility Distribution. Ilk J Ilm. 2018;10(1):100-4. 